\title{
Localization of the ATP-binding cassette (ABC) transport proteins PfMRPI, PfMRP2, and PfMDR5 at the Plasmodium falciparum plasma membrane Reginald A Kavishe ${ }^{1,3}$, Jeroen MW van den Heuvel ${ }^{1}$, Marga van de Vegte- Bolmer $^{2}$, Adrian JF Luty ${ }^{2}$, Frans GM Russel ${ }^{1}$ and Jan B Koenderink*1
}

Address: ${ }^{1}$ Department of Pharmacology and Toxicology 149, Radboud University Nijmegen Medical Centre, P.O. Box 9101, 6500 HB Nijmegen, the Netherlands, ${ }^{2}$ Department of Medical Microbiology 268, Radboud University Nijmegen Medical Centre, P.O. Box 9101,6500 HB Nijmegen, the Netherlands and ${ }^{3}$ Kilimanjaro Christian Medical College of Tumaini University, P. O. Box 2240, Moshi, Tanzania

Email: Reginald A Kavishe - R.Kavishe@ncmls.ru.nl; Jeroen MW van den Heuvel - J.vandenHeuvel@ncmls.ru.nl; Marga van de VegteBolmer - M.vandeVegte@mmb.umcn.nl; Adrian JF Luty - A.Luty@mmb.umcn.nl; Frans GM Russel - F.Russel@ncmls.ru.nl;

Jan B Koenderink* - J.Koenderink@ncmls.ru.nl

* Corresponding author

Published: 28 August 2009

Malaria Journal 2009, 8:205 doi:10.1186/1475-2875-8-205
Received: 3 June 2009

Accepted: 28 August 2009

This article is available from: http://www.malariajournal.com/content/8/I/205

(C) 2009 Kavishe et al; licensee BioMed Central Ltd.

This is an Open Access article distributed under the terms of the Creative Commons Attribution License (http://creativecommons.org/licenses/by/2.0), which permits unrestricted use, distribution, and reproduction in any medium, provided the original work is properly cited.

\begin{abstract}
Background: The spread of drug resistance has been a major obstacle to the control of malaria. The mechanisms underlying drug resistance in malaria seem to be complex and multigenic. The current literature on multiple drug resistance against anti-malarials has documented PfMDRI, an ATP-binding cassette $(A B C)$ protein, as an important determinant of resistance. In the Plasmodium falciparum genome, there are several $A B C$ transporters some of which could be putative drug transporting proteins. In order to understand the molecular mechanisms underlying drug resistance, characterization of these transporters is essential. The aim of this study was to characterize and localize putative $A B C$ transporters.
\end{abstract}

Methods: In the plasmoDB database, 16 members of the $P$. falciparum ABC family can be identified, II of which are putative transport proteins. A phylogenetic analysis of the aligned NBDs of the PfABC genes was performed. Antibodies against PfMRPI (PfABCCI), PfMRP2 (PfABCC2), and PfMDR5 (PfABCB5) were generated, affinity purified and used in immunocytochemistry to localize the proteins in the asexual stages of the parasite.

Results: The $A B C$ family members of $P$. falciparum were categorized into subfamilies. The $A B C B$ subfamily was the largest and contained seven members. Other family members that could be involved in drug transport are PfABCCI, PfABCC2, PfABCGI, and PfABCI3. The expression and localization of three $A B C$ transport proteins was determined. PfMRPI, PfMRP2, and PfMDR5 are localized to the plasma membrane in all asexual stages of the parasite.

Conclusion: In conclusion, II of the 16 ABC proteins in the $P$. falciparum genome are putative transport proteins, some of which might be involved in drug resistance. Moreover, it was demonstrated that three of these proteins are expressed on the parasite's plasma membrane. 


\section{Background}

Drug resistance is a major problem in malaria. Today only a limited number of effective anti-malarials is available. An important reason for therapeutic failure in malaria treatment could be that drugs do not reach their target sites, due to active extrusion by the parasite. The transport proteins responsible for this type of resistance are socalled multidrug resistance proteins (MDR/MRP), most of which belong to the superfamily of ATP binding cassette (ABC) proteins, one of the largest protein families. Many of these plasma membrane proteins actively pump out a wide range of structurally and functionally diverse amphipathic drugs, thereby decreasing the intracellular drug accumulation and resulting in drug resistance $[1,2]$. The structure of a typical ABC transporter consists of six trans-membrane segments that form a trans-membrane domain (TMD) and the Walker A and Walker B motifs that form a nucleotide binding domain (NBD) (Figure 1). $\mathrm{ABC}$ transporters are either encoded as full transporters (TMD-NBD-TMD-NBD) or as half transporters (TMDNBD) that upon translation combine to form a functional unit. Apart from their normal physiological role, ABC transporters are involved in various diseases either by a mutation or through an altered mode of their expression $[3,4]$.

Several polymorphisms and an increased copy number of the Plasmodium falciparum MDR1 have been associated with drug resistance [5]. Heterologous expression data indeed show that PfMDR1-mediated anti-malarial drug transport is affected by some of these polymorphisms $[6,7]$. The other member of the PfABC B family that has been characterized is the half transporter PfMDR2 that confers heavy metal resistance to $P$. falciparum and most likely is not involved in drug resistance [8]. Finally, PfMRP1 polymorphisms have been associated with drug

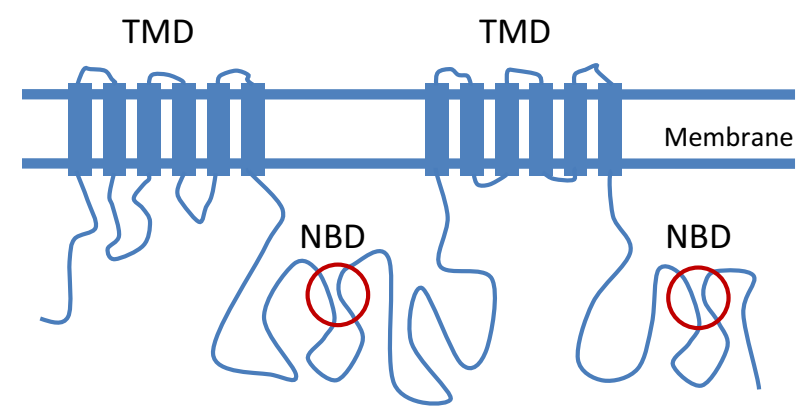

Figure I

Typical structure of an ABC full transporter. The TMDs each contain 6 trans-membrane (TM) segments and the NBDs contain the Walker $A$ and Walker $B$ motifs. ABC half transporters consists of one TMD and one NBD that upon translation combine to form a functional unit. resistance and recently it has been shown that PfMRP1 transports anti-malarial drugs and glutathione [9]. PfMDR1 has been detected in the membrane of the food vacuole [10], which is in contrast to PfMRP1 that has been immunelocalized in the plasma membrane of the parasite $[9,11]$. In previous studies the P. falciparum ABC family members were identified $[12,13]$ and categorized $[14,15]$. In this study, the P. falciparum ABC transporter family has also been categorized and the database sequence of PfMRP1, PfMRP2, and PfMDR5 was confirmed. Moreover, with immunocytochemistry techniques it was shown that all three transporters are probably present in the plasma membrane of the parasite during the asexual erythrocytic stages.

\section{Methods \\ Parasite culture, extraction and DNA isolation}

NF54 (Amsterdam airport) strain of $P$. falciparum was cultured as described by Ponnudurai et al [16]. The culture medium [17] was changed twice daily. Infected blood culture was centrifuged at $1000 \mathrm{~g}$ for 5 minutes to collect RBCs. After washing twice with PBS the cells were resuspended in $0.05 \%$ saponin in PBS and incubated at $37^{\circ} \mathrm{C}$ for 30 minutes. Then the sample was centrifuged at 2000 $\mathrm{g}$ for 10 minutes to collect the parasites. Parasite cells were washed twice with PBS and genomic DNA was isolated using the QIAamp DNA mini kit (Qiagen, Venlo, The Netherlands) following the cultured cells protocol as directed by the manufacturer. RNA was isolated using standard Trizol (guanidinium isothiocyanate) method. Briefly, $500 \mu$ Trizol reagent (Invitrogen) was added to the parasite pellet followed with $2.5 \mu$ l glycogen solution $(18 \mathrm{mg} / \mathrm{ml})$, the mixture was homogenized with pipette and incubated on ice for $5 \mathrm{~min} 50 \mu \mathrm{l}$ chloroform was added and after shaking thoroughly the mixture was incubated on ice for $10 \mathrm{~min}$. Centrifugation at 13,000 $\mathrm{g}$ for 15 min at $4^{\circ} \mathrm{C}$ separated the mixture into upper aqueous and lower chloroform phases. The aqueous phase which contains RNA was transferred into a fresh tube and $240 \mu \mathrm{l}$ isopropyl alcohol was added, mixed by vortex and incubated on ice for $10 \mathrm{~min}$ prior to centrifugation at 13,000 $\mathrm{g}$ for 20 $\min$ at $4^{\circ} \mathrm{C}$. The supernatant was discarded and the RNA pellet was air-dried and dissolved in $20 \mu \mathrm{l}$ DEPC treated water. RNA was stored at $-20^{\circ} \mathrm{C}$ until use.

\section{Sequencing of PfMRPI, PfMRP2, and PfMDR5}

cDNA was synthesized with superscript-II reverse transcriptase and oligo-dT primers (Invitrogen). PCR for the ABC genes was performed on cDNA using Takara LA Taq. PCR protocol was followed as outlined on Takara protocol except that annealing was done at $58^{\circ} \mathrm{C}$ for $30 \mathrm{sec}$, extension at $62^{\circ} \mathrm{C}$ for $10 \mathrm{~min}, 25$ cycles with final extension $72^{\circ} \mathrm{C}$ for 5 minutes. The PCR product was PEG-purified and cloned into pDONR-221 entry-vector using BP 
clonase kit (Invitrogen) following manufacturer's instructions. Sequencing was performed using ABI3730 analyzer (Applied biosystems Inc.).

\section{Antibodies}

PfMRP1 polyclonal antibody was raised in rabbits against the specific peptides ${ }^{215}$ CSNNNHLQNPDAFY228 and ${ }^{1420}$ YASGIIKLYKEKNYV 1434 as described by Klokousas et al [11] (Eurogentec, Belgium), whereas the PfMDR5 polyclonal antibody was designed and produced in rabbits (EZ Biolab, USA) against the peptide ${ }^{730}{ }^{73}$ QSTKYNSQCYQKNK ${ }^{744}$ in the cytosolic loop of the protein. For PfMRP2 a GST-fusion peptide was produced in Escherichia coli using pGEX-3X vector. This peptide corresponds to a 70 amino acid long region within the cytosolic loop of PfMRP2 represented by the sequence: LHYEGNLVDYIKKNNIVVKEDIVQTNKQCEKKSLTNEQV KSMLSLNEDWNYMHRVKKKSITQKETTKNYD. The peptide was extracted and purified from E. coli using glutathione-agarose beads (BD Biosciences). $2 \mathrm{ml}$ of the purified peptide was subcutaneously injected into rabbits followed with a $1^{\text {st }}$ and $2^{\text {nd }}$ boost on day 21 and 42 , respectively. Pre-immune serum was taken on day zero and after 63 days serum was collected. For immuno-localization experiments, the polyclonal sera for PfMRP1 and PFMDR5 were affinity purified using Sulfolink immobilization kit for peptides (Thermo scientific, USA) while for PfMRP2 the Affigel-15 kit (Bio-Rad Laboratories) was used as described by the manufacturers.

\section{Immuno-localization}

Infected RBCs were fixed in 4\% paraformaldehyde for 10 minutes at room temperature then washed once with PBS. The cells were applied on poly-L-lysine coated slide cover slips (12 mm, Menzel GmbH \& co KG, Germany) and air dried for 5 - 10 minutes. Cover slips were quenched with $0.15 \%$ glycine in $0.5 \%$ PBS-tween 20 (PBST) for $10 \mathrm{~min}$ utes at room temp followed by washing twice with PBST and incubation with $0.1 \%$ tritonX100 (BDH chemicals) for 45 minutes at room temp. After washing once with PBST, blocking was done with normal goat serum (Zymed, USA) for $1 \mathrm{hr}$ at room temp followed with washing once with PBST. Cover slips were then incubated with primary antibody: rabbit polyclonals and mouse antiPfERC (MR4, MRA-87 Pf39 mouse antiserum, deposited by TJ Templeton) or mouse anti-glycophorin A monoclonals (Caltag laboratories, Invitrogen) at $4{ }^{\circ} \mathrm{C}$ overnight followed with three times washing each for 20 minutes with PBST at room temperature. The secondary antibodies Alexa 594 goat anti-rabbit and Alexa 488 goat anti-mouse monoclonals (Molecular probes, The Netherlands) were applied on the cover slips for $2 \mathrm{hrs}$ at room temperature. After rinsing two times with PBST, the cover slips were incubated for 30 minutes with DAPI followed with $2 \times 20$ minutes washing with PBST at room temperature. The cover slips were then briefly air-dried in the dark and mounted on microscope slides (Menzel GmbH \& co KG, Germany) using Dako fluorescent mounting medium (Dako North America Inc., Carpinteria USA). Slides were imaged using a confocal microscope (Olympus FV1000). Image J free software version 1.43 was used to process images.

\section{Results \\ Identification and characterization of $A B C$ transport proteins}

In the plasmoDB database, a PFAM (PF00005:ABC_tran $\mathrm{ABC}$ transporter) search for $\mathrm{ABC}$ transport proteins in $P$. falciparum resulted in 16 hits. PfMDR1 (PFE1150w), PfMDR2 (PF14_0455), and PfMRP1 (PFA0590w) are hits that have been described in literature by several groups [8$10]$, but the other family members have not been the subject of investigation yet. In this study it was determined if the family members are full (two NBDs) or half transporters (one NBD). Next the NBD (30 amino acids before Walker A until Walker B) were aligned with ClustalW2 [18]. Part of the aligned sequence with the Walker A (GxxGxGKST or [AG]xxxxGK [ST]), the ABC signature sequence (LSGGQ), and Walker B (hhhhDEPT or DExxxxxD) are shown in Figure 2. The phylogenetic data was imported in TreeView [19] and visualized as a phylogram in Figure 3. A blast search against human proteins clearly shows that there are no members of the A subfamily. However, $P$. falciparum contains 11 putative transport proteins containing TMDs that belong to the $\mathrm{B}, \mathrm{C}, \mathrm{G}$ and I subfamilies. In addition, there are five $A B C$ family members that do not contain a TMD. Three of these belong to the $\mathrm{E}$ and $\mathrm{F}$ subfamilies, whereas the other two members were classified in the I subfamily that was introduced for the plant $\mathrm{ABC}$ proteins recently [20]. The numbering within each subfamily is shown in Table 1 and was done according to the existing chronological numbering (PfMDR1, PfMDR2, PfMRP1, and PfMRP2). Moreover, neighbouring $\mathrm{ABC}$ members in the phylogenetic tree obtained sequential numbering. The numbers do not carry additional information, such as a relationship with $\mathrm{ABC}$ transporters of other species. The domain organization was established by analysis of the sequences with SMART [21].

This study focuses on PfMRP1 (PFA0590w), PfMRP2 (PFL1410c), and PfMDR5 (PF13_0218), because their antibody generation was successful. PfMRP1 and PfMRP2 are both full transporters that belong to the ABC C family, whereas PfMDR5 is a half transporter that belongs to the ABC B family. For these three transporters, the trans-membrane segments were determined with TMHMM [22]. Some of the trans-membrane segments were not predicted, but weak probabilities of TM helices were assigned as such in order to obtain the correct $\mathrm{ABC}$ trans-mem- 


PF14_0455
PFE1150w-b
PFE1150w-a
PF11_0466
PFC0125w
PF13_0218
PF13_0271
PFL0495c
PFA0590w-b
PFL1410c-b
PFA0590w-a
PFL1410c-a
PF14_0133
PF14_0244
PF11_0225-b
PF08_0078-b
PF08_0078-a
PF11_0225-a
MAL13P1.344-b
MAL13P1.344-a
PF14_0321
PFC0875w

IKPGTTCALVGHTGSGKTT I SKLLYRF CDSKKTTAIVGETGSGKSTFMNLLLRF LKEGKTYAFVGESGCGKSTILKLIERL IYKNTNNVI IGKSGGGKSTILKLILNM FSNKYTYGILCYNDSGKNYLAKLAARL IKASEKVAIIGKSGSGKSTLWKLLTCN IENGEKVAI IGKSGSGKSSLIKLLLKF LP HNKSVAIVGKSGSGKTT I LNLLTKK ALKNQKIGIVGKS GAGKSTILLS ILGL ALKNQKIGIVGKSGAGKSTMILSILGL LKRNSLAI I I GNVGSGKSAFFHS I LGD LKNNSVVIILGNVGSGKTIFFYSLLGQ IYLGEKHTIMGRNGSGKSTLAKVIAGH LLPKTITVIMGP SGSGKTTLLNILSMK VDMDSRIAICGVNGSGKTTLIKIILNL INSGENVLLLGKNGIGKSTLFKILTNK LNKTECIGLIGNNGCGKTTLLNLIYEN INVMNKYGLIGKNGIGKSTLLAKLARY FSESEIFVLLGQNGSGKSTF IRLFAGL PKLGQILGLVGTNGIGKSTALKILSSK FERGMRILVCGKNGAGKSTLLS I IAGK LRSNRIFVLLGENGSGKSTLINIITKM

$$
\text { Walker }{ }^{* *} \text {. }
$$

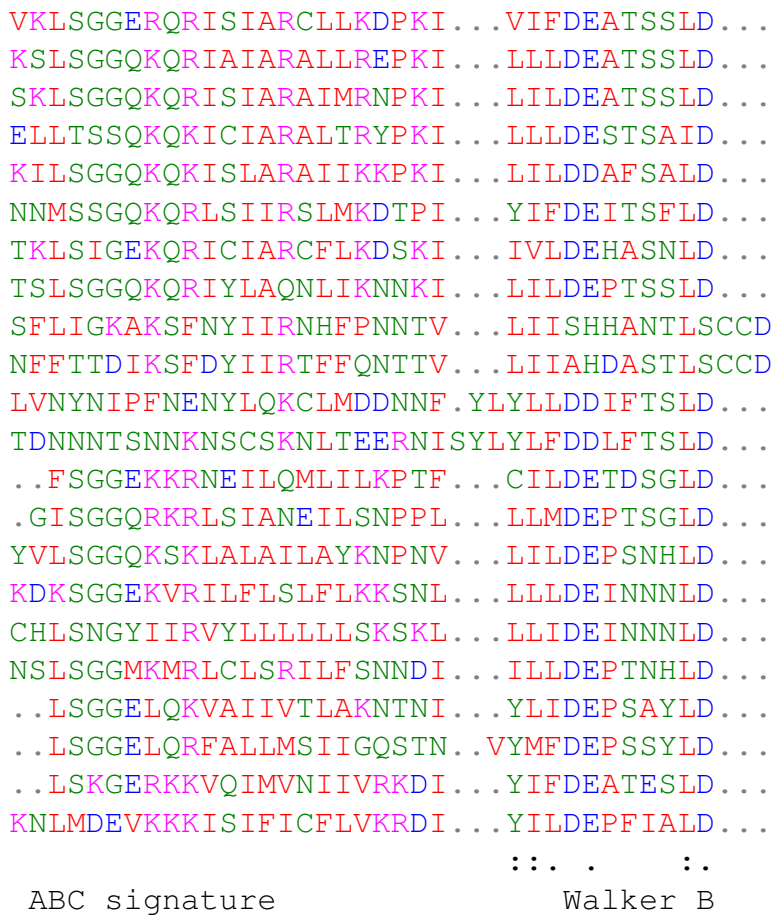

\section{Figure 2}

NBD alignment of $\boldsymbol{P}$. falciparum ABC superfamily. The figure shows a part of the with ClustalW2 aligned sequence with Walker A (GxxGxGKST or [AG]xxxxGK [ST]), ABC signature sequence (LSGGQ), and Walker B (hhhhDEPT or DExxxxxD). $x$ is any amino acid whereas $h$ is a hydrophobic amino acid.

brane domains with six trans-membrane segments (Table 2). PfMRP1, PfMRP2, and PfMDR5 genes were sequenced and the results matched the published data and no polymorphisms were observed.

\section{Localization of PfMRPI, PfMRP2, and PfMDR5}

Polyclonal antibodies were generated by immunization of rabbits with specific peptides for the $P$. falciparum $\mathrm{ABC}$ proteins. Blast searches with the peptides showed no relevant specific hits with other proteins. To minimize aspecific binding immuno-purified antibodies against the peptide were used for immuno-localization studies. The glycophorin-A antibody was used to stain erythrocyte membranes thus contrasting them from parasite cells while the PfERC antibody, which binds to an intracellular calcium binding protein located on the endoplasmic reticulum, was used to determine intracellular localization of the pfABCs.

PfMRP1 localized to the parasites plasma membrane and no signal was observed on the erythrocyte membrane or in the region around the food vacuole. In the differential interface contrast image the food vacuole can be recognized from its dark-spot appearance (presence of haemo- zoin crystals). These results are consistent with those reported in a recent study [9] in which plasma membrane localization of PfMRP1 was reported also, with possible intracellular expression. The results in this study show the signal to be intense on the outside, forming a clear rim in what can be interpreted as the parasite's plasma membrane especially in the ring and trophozoite stages (Figures 4A-D). More clearly cytoplasmic staining was evident in the schizont stages (Figures $4 \mathrm{~B}, \mathrm{C}$, and $4 \mathrm{E}$ ), interpreted as plasma membrane partitions of the dividing parasites. Unfortunately, due to their small size detailed high magnification imaging of the non-dividing stages such as rings and young trophozoites was limited by the light resolution power of the microscope. PfMRP1 did not co-localize with PfERC, thus suggesting the absence of PfMRP1 on the endoplasmic reticulum membrane.

For PfMRP2 specific staining was observed on the parasite's plasma membrane (Figure 5, column 2). Low intensity signal was occasionally observed intracellularly especially in early schizont stages (Figure 5, D2) which can be considered to be plasma membrane partitions as the parasite undergoes cytokinesis. This is especially so as 


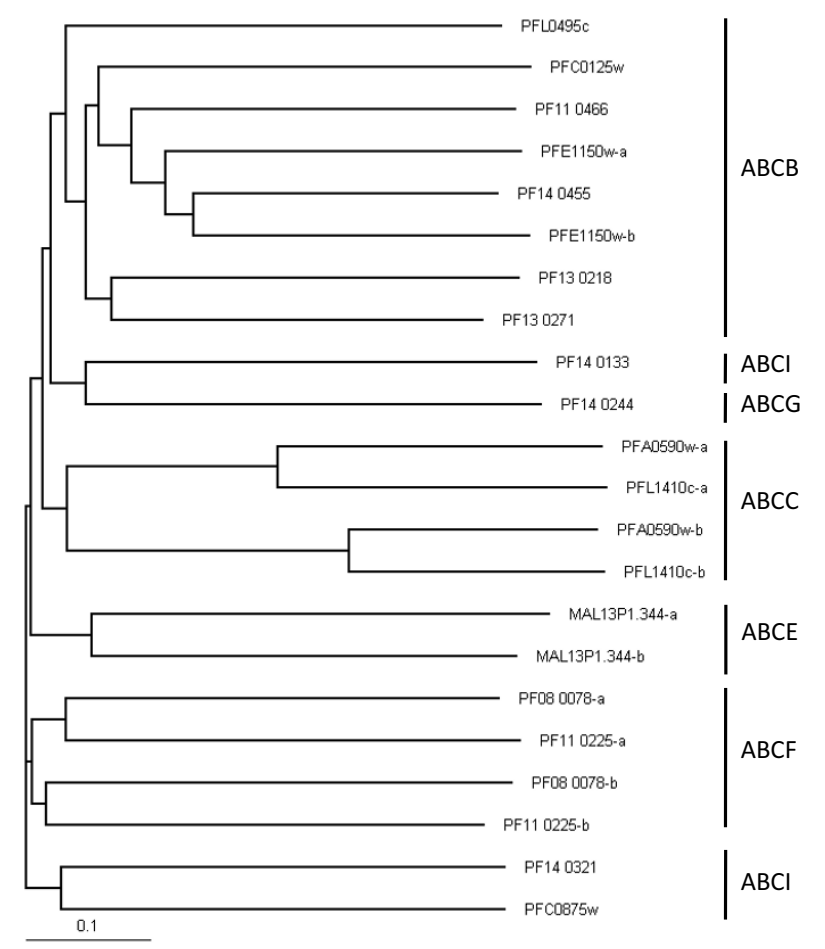

Figure 3

Phylogram of the $\boldsymbol{P}$. falciparum ABC superfamily. The NBDs were aligned and the phylogenetic data was imported in TreeView. In combination with blast searches the ABC transport proteins were categorized in subfamilies.

each of these partitions enclose a nucleus as clearly stained by DAPI (Figure 5, D4). PfMRP2 did not co-localize with PfERC in the endoplasmic reticulum (Figure 5C and 5D) and no staining was observed in the region presumed to be the food vacuole (shown by arrow in Figure 5, C5).

PfMDR5 was clearly observed to localize to the surface of the parasite in all asexual stages (Figure 6). Trophozoite stages sometimes revealed a less intense intracellular staining around the food vacuole (Figure 6, B5 and D5). This pattern of staining though sometimes strong, was not consistent in the many slides scanned. Instead the staining was sometimes seen around the nuclei of dividing trophozoites, which may also suggest these to be plasma membrane partitions as the trophozoite divides. Moreover, in the schizont stages the region covered by the food vacuole did not show any obvious staining with the PfMDR5 antibody, instead clear partitions were seen separating each of the individual nuclei (Figure 6, 2C). In comparison with the endoplasmic reticulum marker PfERC, which localized as bright staining patches within the parasite, PfMDR5 localized differently, forming a rim outside the PfERC staining in all stages (Figure 6D-F) (ring stages not shown). Therefore, it is concluded that PfMDR5 is primarily expressed on the plasma membrane.

\section{Discussion}

In the plasmoDB database 16 members of the P. falciparum ABC family can be identified, 11 of which could be putative drug efflux transporters. A phylogenetic analysis of the PfABC genes was performed and the genes were categorized into seven subfamily groups. Three ABC family members were analysed in more detail and their expression in all erythrocytic stages as well as their localization at the plasma membrane of the parasite was demonstrated.

Development of resistance against newly introduced antimalarials can be rapid especially in malaria endemic regions where drug pressure is high. For instance mefloquine was introduced in Thailand in 1984 as a very potent drug against multidrug resistant malaria, but six years later significant resistance had developed [23]. Multiple studies have demonstrated the role of PfMDR1 polymorphisms in multidrug resistant malaria. It was shown that the antimalarial drugs halofantrine, quinine and chloroquine are transported by PfMDR1 [7]. Moreover, polymorphisms within PfMDR1 alter the substrate specificity for these anti-malarial drugs [7]. Recent association studies have linked single nucleotide polymorphisms on PfMRP1 with reduced parasite response to anti-malarial drugs [24,25] and expression of both PfMRP1 and PfMRP2 were up-regulated by mefloquine and chloroquine in laboratory cultures of both drug sensitive and resistant strains [26]. This indicates that $\mathrm{ABC}$ transporters play a role in malaria chemotherapy [27]. The knowledge that other PfABC family members could be capable of drug transport indicates that it is likely that some of these transport proteins might play a role in emerging drug resistance. Further identification and characterization of these ABC transporters will provide information on their putative role in resistance and may provide novel targets to control and perhaps prevent spread of resistance against other efficacious drugs.

The PFAM search in plasmoDB resulted in 16 ABC family members that were also identified and catagorized by others [12-15]. ABC A subfamily members were not observed, but these seem to be absent in all Apicomplexa. The ABC B subfamily consists of seven members of which only PfMDR1 is a full transporter. The $\mathrm{C}$ subfamily contains two full transporters, whereas the G subfamily contains one half transporter. Next to these ABC family members there is one additional member that contains a TMD. As this member does not belong to the existing subfamilies, it was placed in the I family that was proposed by Verrier 
Table I: The Plasmodium falciparum ABC superfamily

\begin{tabular}{|c|c|c|c|c|}
\hline Subfamily & Gene identification & & Domain organisation & Amino acids \\
\hline \multicolumn{5}{|l|}{ ABCB } \\
\hline$A B C B I$ & PFEII50w & PfMDRI & $(\mathrm{MSD}-\mathrm{NBD})_{2}$ & 1419 \\
\hline $\mathrm{ABCB} 2$ & PFI4_0455 & PfMDR2 & MSD-NBD & 1024 \\
\hline $\mathrm{ABCB} 3$ & PFII_0466 & & MSD-NBD & 872 \\
\hline $\mathrm{ABCB} 4$ & $\mathrm{PFCO} 25 \mathrm{w}$ & & MSD-NBD & 1365 \\
\hline $\mathrm{ABCB} 5$ & PFI3_0218 & & MSD-NBD & 925 \\
\hline $\mathrm{ABCB} 6$ & PFI3_027I & & MSD-NBD & 1049 \\
\hline $\mathrm{ABCB7}$ & PFL0495c & & MSD-NBD & 855 \\
\hline \multicolumn{5}{|l|}{$A B C C$} \\
\hline $\mathrm{ABCCl}$ & PFA0590w & PfMRPI & $(\mathrm{MSD}-\mathrm{NBD})_{2}$ & 1822 \\
\hline $\mathrm{ABCC} 2$ & PFLI4IOc & PfMRP2 & $(\mathrm{MSD}-\mathrm{NBD})_{2}$ & 2108 \\
\hline \multicolumn{5}{|l|}{ ABCE } \\
\hline$A B C E I$ & MALI3 PI.344 & & $(\mathrm{NBD})_{2}$ & 619 \\
\hline \multicolumn{5}{|l|}{ ABCF } \\
\hline$A B C F I$ & PFII_0225 & & $(\mathrm{NBD})_{2}$ & 815 \\
\hline$A B C F 2$ & $\begin{array}{l}\text { PfGCN20 } \\
\text { PF08_0078 }\end{array}$ & & $(\mathrm{NBD})_{2}$ & 1419 \\
\hline \multicolumn{5}{|l|}{ ABCG } \\
\hline ABCGI & PFI4_0244 & & NBD-MSD & 660 \\
\hline \multicolumn{5}{|l|}{$\mathrm{ABCl}$} \\
\hline $\mathrm{ABCII}$ & PFI4_0133 & & NBD & 347 \\
\hline $\mathrm{ABCl} 2$ & PFI4_032I & & NBD & 171 \\
\hline $\mathrm{ABCl} 3$ & $\mathrm{PFC} 0875 \mathrm{w}$ & & MSD-NBD-MSD & 3133 \\
\hline
\end{tabular}

et al [20] to harbour "orphan" ABC components. Five ABC family members that do not contain TMDs are located in E, F, and I subfamilies.

Recently, Gangwar and colleagues [14] analysed the ABC family members of $P$. falciparum, their phylogenetic tree was, however, not based on an alignment of the conserved

Table 2: Trans-membrane segments of PfMRPI, PfMRP2, and PfMDR5.

\begin{tabular}{llll}
\hline TM & PfMRPI & PfMRP2 & PfMDR5 \\
\hline 1 & $121-143$ & $133-155$ & $88-111$ \\
2 & $175-197$ & $180-202$ & $143-163$ \\
3 & $318-340$ & $402-424$ & $181-203$ \\
4 & $350-372$ & $434-456$ & $270-292$ \\
5 & $426-448$ & $517-539$ & $365-387$ \\
6 & $466-488$ & $554-575$ & $399-417$ \\
7 & $1158-1180$ & $1430-1452$ & \\
8 & $1218-1240$ & $1473-1495$ & \\
9 & $1250-1272$ & $1510-1532$ & \\
10 & $1293-1310$ & $1553-1570$ & \\
11 & $1314-1333$ & $1574-1593$ & \\
12 & $1392-1414$ & $1654-1676$ & \\
\hline
\end{tabular}

The TM segments were predicted with TMHMM. TM segments in italic were weak probabilities.
NDB regions but on the whole protein, which results in a phylogenetic tree where the subfamilies are not clustered. Moreover, they did not include ABCB4 (PFC0125w) in their analyses and included PFE0450w, which is not an ABC family member but a putative chromosome condensation protein. In a very recent review by Sauvage et al [15] the $\mathrm{ABC}$ families of different protozoan parasites were listed. They clustered the ABC family members in a way similar to our approach. In this study PF08_0078 was, however, assigned in the F family according to the phylogenetic analysis of both NBDs, whereas they categorized it as "other". As they did not show a phylogenetic analysis it is not clear why this discrepancy exists. Moreover, PFC0875w (PfABCI3), that does not possess a clear ABC signature motif, but according to the PFAM search belongs to the ABC family, is not listed in their overview. In this study the existing nomenclature for PfMDR1, PfMDR2, and PfMRP1, was not changed, but the nomenclature of Verrier et al [20] for plant ABC proteins that was adopted from the HUGO nomenclature and discussed in several international meetings was used. This nomenclature essentially constitutes a catalogue with numbered entries, where the numbers do not necessarily carry additional information, although the subfamily assignment does indeed convey information about phylogenetic relation- 


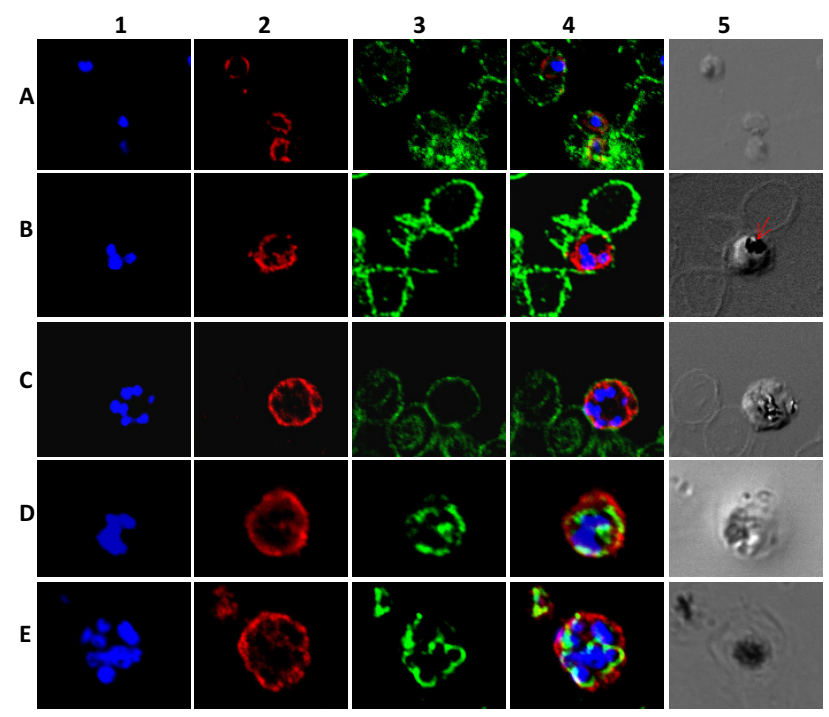

Figure 4

Localization of PfMRP I within the asexual stages of P. falciparum. In column I blue (DAPI) shows the nuclear staining. In column 2 red shows PfMRPI staining. In column 3 green shows glycophorin $A(A, B$, and $C)$ or PfERC (D and $E)$ staining. Column 4 shows the merge of column I-3. Finally, column 5 shows the differential interference contrast image. Represented in rows: A, rings; B, early schizont; C, schizont; $D$, trophozoite; $E$, schizont and ring. The arrow indicates the food vacuole.

ships [20]. The gene nomenclature recently published by Sauvage et al [15] is based on the nomenclature for Toxoplasma gondii [28], which as a consequence in $P$. falciparum resulted in the absence of ABCB2, ABCG1, ABCG2, $\mathrm{ABCH} 1$, and $\mathrm{ABCH} 3$ and the relocation of PfMDR2 to ABCB3. Such a nomenclature is, however, impractical for a group with relatively few orthologous pairings, such as the ABCs [20].

It is known that the malaria parasite can express its membrane proteins on at least four different subcellular sites: on its membrane-bound organelles, the plasma membrane, the parasitophorous vacuolar membrane and on the plasma membrane of its host erythrocyte [29,30]. The expression of PfMRP1, PfMRP2, and PfMDR5 was observed on the outside of the parasite. It is practically impossible to distinguish the plasma membrane from the parasitophorous vacuolar membrane by immunocytochemistry. However, a detailed look at the expression of all three $\mathrm{ABC}$ transporters shows that they are also present on membranes between parasitic nuclei in the multinuclear stages of development. As these are plasma membranes in the process of formation, it is concluded that all three $\mathrm{ABC}$ transport proteins are located on the plasma
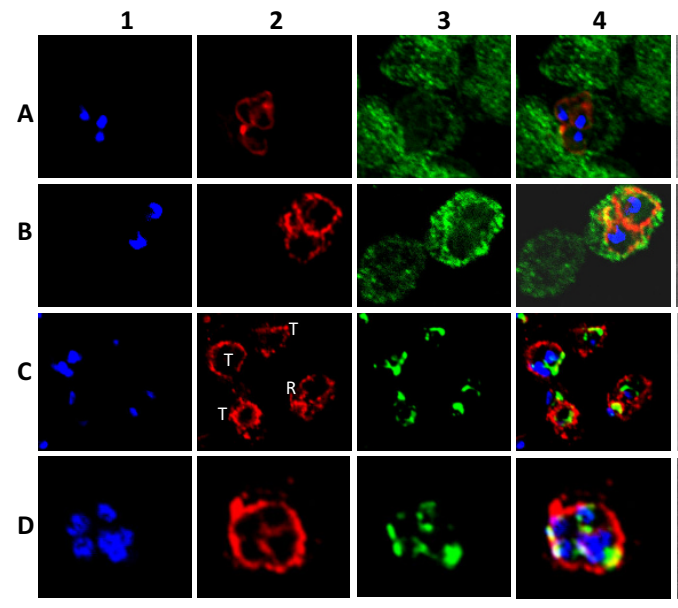

5

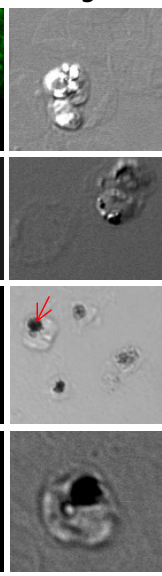

Figure 5

Localization of PfMRP2 within the asexual stages of $P$. falciparum. In column I blue (DAPI) shows the nuclear staining. In column 2 red shows PfMRP2 staining. In column 3 green shows glycophorin-A (A and $B)$ or PfERC (C and $D)$ staining. Column 4 shows the merge of column I-3. Finally, column 5 shows the differential interference contrast image. Represented in rows: A, multiple infected erythrocyte: rings; $B$, double infected erythrocyte: trophozoites; $C$, three trophs $(T)$ and two rings (R); D, early schizont. Arrow indicates food vacuole.

membrane in all asexual erythrocytic stages of $P$. falciparum. The localization of PfMRP1 at the plasma membrane has been shown by others $[9,11]$. An elegant control was shown in the recent study of Ray et al [9], where a $P$. falciparum knock-out of PfMRP1 was used. In this study, knock-out parasites were not available and as an additional control the antibody was affinity purified with the peptide that was used to immunize the rabbits. In addition, background staining with the erythrocytes was not observed indicating that the staining was specific.

\section{Conclusion}

$16 \mathrm{ABC}$ proteins were categorized according the phylogenetic tree that was constructed from the aligned NBDs. PfMRP1, PfMRP2, and PfMDR5 were localized at the plasma membrane of the parasite throughout the asexual stages. This localization emphasizes the putative role of drug exporters of these ABC family members. Indeed, Ray et al [9] have shown that PfMRP1 plays a role in the efflux of glutathione, chloroquine, and quinine and contributes to parasite responses to multiple anti-malarial drugs, possibly by pumping drugs outside the parasite. PfMRP2 and PfMDR5 might have similar roles and thereby broadening the capacity of the parasite to extrude toxic compounds. Additional research is required to test this hypothesis. 


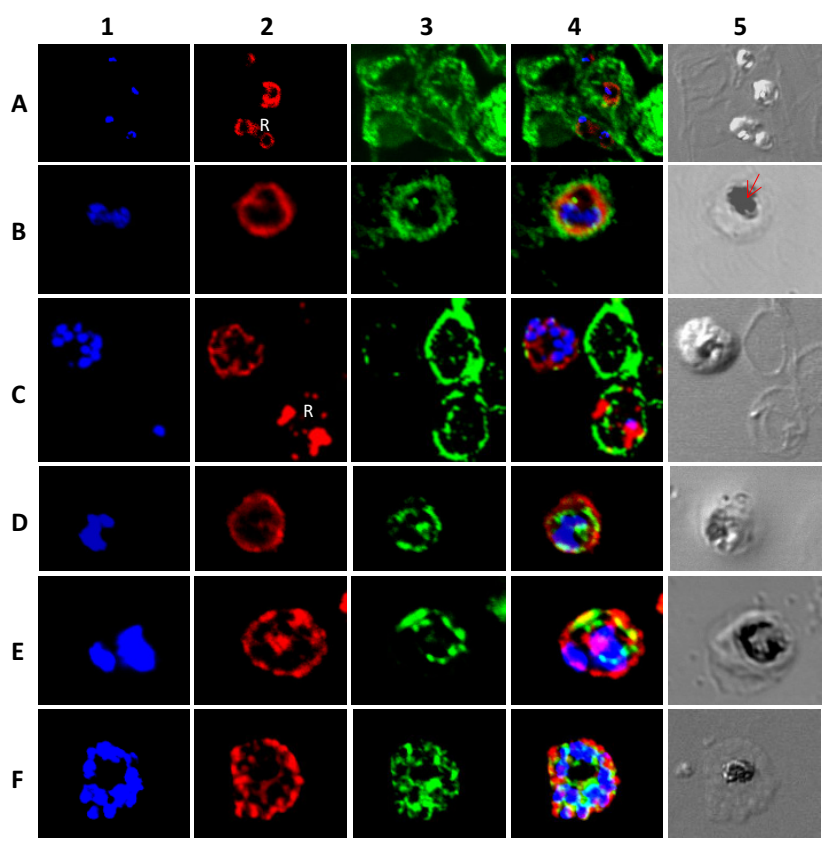

Figure 6

Localization of PfMDR5 within the asexual stages of P. falciparum. In column I blue (DAPI) shows the nuclear staining. In column 2 red shows PfMDR5 staining. In column 3 green shows glycophorin-A $(A, B$, and $C)$ or PfERC $(D, E$, and $\mathrm{F})$ staining. Column 4 shows the merge of column I-3.

Finally, column 5 shows the differential interference contrast image. Represented in rows: $A$, rings; $B$, trophozoite; $C$, schizont and ring (R); $D$, early trophozoite; $E$, dividing trophozoite; F, schizont. Arrow indicates food vacuole

\section{Competing interests}

The authors declare that they have no competing interests.

\section{Authors' contributions}

RAK carried out the cloning, sequencing and immunolocalization experiments and drafted the manuscript. JJMWH participated in cloning, sequencing and immunolocalization experiments. MVB carried out the parasite culture. AJFL participated in its design and supervision and helped draft the manuscript. FGMR participated in its design and supervision and helped draft the manuscript. JBK carried out the phylogenetic analysis, conceived of the study, participated in its design and coordination and helped to draft the manuscript. All authors read and approved the final manuscript.

\section{References}

I. Dassa E, Bouige P: The ABC of ABCs: a phylogenetic and functional classification of $A B C$ systems in living organisms. Res Microbiol 200I, I52:21 I-229.

2. Dean M, Rzhetsky A, Allikmets R: The human ATP-binding cassette (ABC) transporter superfamily. Genome Res 200I, II:II56-II66.
3. Dean M, Annilo T: Evolution of the ATP-binding cassette (ABC) transporter superfamily in vertebrates. Annu Rev Genomics Hum Genet 2005, 6: I 23-1 42.

4. Klokouzas A, Shahi S, Hladky SB, Barrand MA, van Veen HW: ABC transporters and drug resistance in parasitic protozoa. Int J Antimicrob Agents 2003, 22:30I-317.

5. Valderramos SG, Fidock DA: Transporters involved in resistance to antimalarial drugs. Trends Pharmacol Sci 2006, 27:594-601.

6. Lekostaj JK, Amoah LE, Roepe PD: A single SI034C mutation confers altered drug sensitivity to PfMDRI ATPase activity that is characteristic of the $\mathbf{7 G 8}$ isoform. Mol Biochem Parasitol 2008, I57: I07-III.

7. Sanchez CP, Rotmann A, Stein WD, Lanzer M: Polymorphisms within PfMDRI alter the substrate specificity for antimalarial drugs in Plasmodium falciparum. Mol Microbiol 2008, 70:786-798.

8. Rosenberg E, Litus I, Schwarzfuchs N, Sinay R, Schlesinger P, Golenser J, Baumeister S, Lingelbach K, Pollack Y: pfmdr2 confers heavy metal resistance to Plasmodium falciparum. J Biol Chem 2006, 28 I:27039-27045.

9. Raj DK, Mu J, Jiang H, Kabat J, Singh S, Sullivan M, Fay MP, McCutchan TF, Su XZ: Disruption of a Plasmodium falciparum multidrug resistance-associated protein (PfMRP) alters its fitness and transport of antimalarial drugs and glutathione. J Biol Chem 2009, 284:7687-7696.

10. Cowman AF, Karcz S, Galatis D, Culvenor JG: A P-glycoprotein homologue of Plasmodium falciparum is localized on the digestive vacuole. J Cell Biol I991, I I 3:1033-1042.

II. Klokouzas A, Tiffert T, van Schalkwyk D, Wu CP, van Veen HW, Barrand MA, Hladky SB: Plasmodium falciparum expresses a multidrug resistance-associated protein. Biochem Biophys Res Commun 2004, 321 : 197-201.

12. Gardner MJ, Hall N, Fung E, White O, Berriman M, Hyman RW, Carlton JM, Pain A, Nelson KE, Bowman S, Paulsen IT, James K, Eisen JA, Rutherford K, Salzberg SL, Craig A, Kyes S, Chan MS, Nene V, Shallom SJ, Suh B, Peterson J, Angiuoli S, Pertea M, Allen J, Selengut J, Haft $D$, Mather MW, Vaidya AB, Martin DM, Fairlamb AH, Fraunholz MJ, Roos DS, Ralph SA, McFadden GI, Cummings LM, Subramanian GM, Mungall C, Venter JC, Carucci DJ, Hoffman SL, Newbold C, Davis RW, Fraser CM, Barrell B: Genome sequence of the human malaria parasite Plasmodium falciparum. Nature 2002, 419:498-5II.

13. Martin RE, Henry RI, Abbey JL, Clements JD, Kirk K: The 'permeome' of the malaria parasite: an overview of the membrane transport proteins of Plasmodium falciparum. Genome Biol 2005, 6:R26.

14. Gangwar D, Kalita MK, Gupta D, Chauhan VS, Mohmmed A: A systematic classification of Plasmodium falciparum P-loop NTPases: structural and functional correlation. Malar J 2009, 8:69.

15. Sauvage V, Aubert D, Escotte-Binet S, Villena I: The role of ATPBinding Cassette (ABC) proteins in protozoan parasites. Mol Biochem Parasitol 2009, 167:81-94.

16. Ponnudurai T, Lensen AHW, Meis JFGM, Meuwissen JHET: Synchronization of Plasmodium falciparum gametocytes using an automated suspension-culture system. Parasitology 1986, 93:263-274

17. Ifediba T, Vanderberg JP: Peptones and calf serum as a replacement for human-serum in the cultivation of Plasmodium falciparum. J Parasitol 1980, 66:236-239.

18. Larkin MA, Blackshields G, Brown NP, Chenna R, McGettigan PA, McWilliam H, Valentin F, Wallace IM, Wilm A, Lopez R, Thompson JD, Gibson TJ, Higgins DG: Clustal $\mathbf{W}$ and Clustal $X$ version 2.0 . Bioinformatics 2007, 23:2947-2948.

19. Page RD: TreeView: an application to display phylogenetic trees on personal computers. Comput Appl Biosci 1996, 12:357-358.

20. Verrier PJ, Bird D, Burla B, Dassa E, Forestier C, Geisler M, Klein M, Kolukisaoglu U, Lee Y, Martinoia E, Murphy A, Rea PA, Samuels L, Schulz B, Spalding EJ, Yazaki K, Theodoulou FL: Plant ABC proteins-a unified nomenclature and updated inventory. Trends Plant Sci 2008, 13:151-159.

21. Letunic I, Doerks T, Bork P: SMART 6: recent updates and new developments. Nucleic Acids Res 2009, 37:D229-D232. 
22. Krogh A, Larsson B, von HG, Sonnhammer EL: Predicting transmembrane protein topology with a hidden Markov model: application to complete genomes. J Mol Biol 200I, 305:567-580.

23. Nosten F, TerKuile F, Chongsuphajaisiddhi T, Luxemburger C, Webster HK, Edstein M, Phaipun L, Thew KL, White NJ: Mefloquineresistant falciparum-malaria on the Thai-Burmese border. Lancet 1991, 337: | |40-1 |43.

24. Mu JB, Ferdig MT, Feng XR, Joy DA, Duan JH, Furuya $T$, Subramanian G, Aravind L, Cooper RA, Wootton JC, Xiong M, Su XZ: Multiple transporters associated with malaria parasite responses to chloroquine and quinine. Mol Microbiol 2003, 49:977-989.

25. Ursing J, Zakeri S, Gil JP, Bjorkman A: Quinoline resistance associated polymorphisms in the pfcrt, pfmdrl and pfmrp genes of Plasmodium falciparum in Iran. Acta Tropica 2006, 97:352-356.

26. Nogueira F, Alves C, Estolio do Rosario V: Plasmodium falciparum multidrug resistance protein (MRP) gene expression under chloroquine and mefloquine challenge. Journal of Cell and Animal Biology 2008, 2:10-20.

27. Price RN, Uhlemann AC, Brockman A, McGready R, Ashley E, Phaipun L, Patel R, Laing K, Looareesuwan S, White NJ, Nosten F, Krishna S: Mefloquine resistance in Plasmodium falciparum and increased pfmdrl gene copy number. Lancet 2004, 364:438-447.

28. Sauvage V, Millot JM, Aubert D, Visneux V, Marle-Plistat M, Pinon JM, Villena I: Identification and expression analysis of ABC protein-encoding genes in Toxoplasma gondii. Toxoplasma gondii ATP-binding cassette superfamily. Mol Biochem Parasitol 2006, 147:177-192.

29. Kirk K, Tilley L, Ginsburg H: Transport and trafficking in the malaria-infected erythrocyte. Parasitol Today 1999, 15:355-357.

30. Krugliak $M$, Ginsburg $\mathrm{H}$ : The evolution of the new permeability pathways in Plasmodium falciparum - infected erythrocytes a kinetic analysis. Exp Parasitol 2006, I | 4:253-258.

Publish with Bio Med Central and every scientist can read your work free of charge

"BioMed Central will be the most significant development for disseminating the results of biomedical research in our lifetime. "

Sir Paul Nurse, Cancer Research UK

Your research papers will be:

- available free of charge to the entire biomedical community

- peer reviewed and published immediately upon acceptance

- cited in PubMed and archived on PubMed Central

- yours - you keep the copyright

Submit your manuscript here:

http://www.biomedcentral.com/info/publishing_adv.asp
BioMedcentral 